\title{
Influence Of THE Forging Process OF THE MACHINED Material ON THE CUTTINg TOOL LifE
}

\author{
Miroslav Zetek, Ivana Zetková \\ University of West Bohemia, Univerzitni 8, 30614 Pilsen, Czech Republic
}

\begin{abstract}
The stability of the machining process is depend on the machined materials properties. But the material properties are influence by the heat treatment process and in this case it is forging. For these study three different company made the "same" forging process and then the material properties are evaluated and their influences on the cutting process were monitored. For the tests the steel DIN $18 \mathrm{CrNiMo}$ 6-7 was used. This material is typically used for the gear wheels where the cutting tools by tool steel is used for the machining. So for the tests the mills from tool steel were used and during the machining the cutting tool life and cutting forces were monitored.
\end{abstract}

Keywords: Gear wheel; Cracks; Forging; Tool wear; Cutting tool life
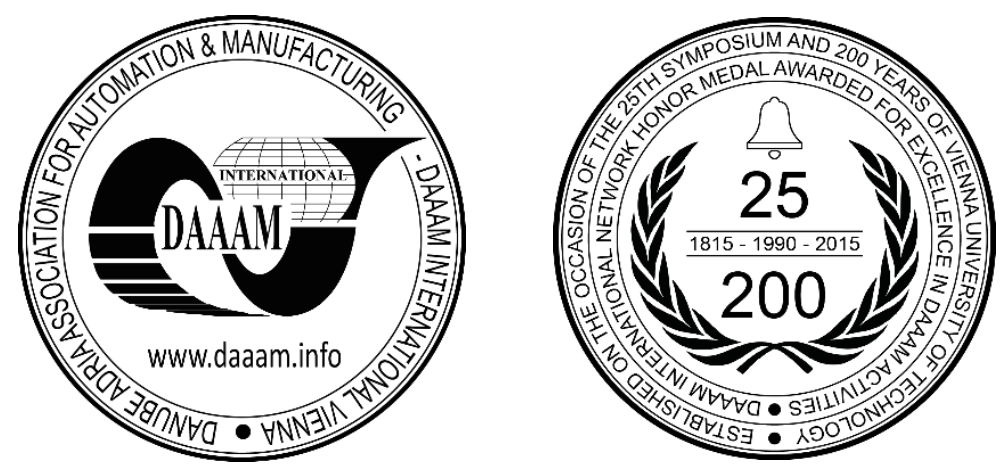

This Publication has to be referred as: Miroslav, Z[etek] \& Ivana, Z[etkova] (2016). Influence of the Forging Process of the Machined Material on the Cutting Tool Life, Proceedings of the 26th DAAAM International Symposium, pp.05420547, B. Katalinic (Ed.), Published by DAAAM International, ISBN 978-3-902734-07-5, ISSN 1726-9679, Vienna, Austria

DOI: $10.2507 / 26$ th.daaam.proceedings.074 


\section{Introduction}

Gears are very commonly using parts where the transmitting and rate change is needed. For their operation is necessary reliability, quiet operation and minimal vibration. It is very important to have a very accuracy tooth surface where the contact is [1]. The surface quality is influenced by the machining technology and strategy. Firstly, standard machining like milling is used and after for higher surface quality the grinding is used. These technologies influence surface defect [2] and could influence future reliability [3]. But these properties is influence by the material properties and by the heat treatment too[4]. When the different process are used it could be cause that the machinability could be change. It could be influence the surface quality and defects. It is a very typically problem when the producers want to change contractors of the material and heat treatment, for example to save money. Normally the material properties is decelerate by the material list where are maximal and minimal value. But in many cases these values could be close to the higher or lower value and in many cases when the heat treatment is used could be changed machinability. Very often the surface structure and hardness is different [5]. It causes changes of cutting tool life, surface quality and surface defect [6]. Problem is that this changes are detect during the machining and machine operator must change cutting parameters or stop process and machining time increase. This happens when the new productive cutting tool are used too. Normally this cutting tools have some shape protection like special mikrogeometry or thin coating [7]. But in cases of gear machining the cutting tools from tool steel are used. This cutting material is very tough and can resist high shock. It is very important because very often in one workpiece the surface mechanical properties are changed and the cutting tool is loaded with different conditions. This same problems have heat resistant alloys during roughing where the structure is changed and cutting tool life decrease very quickly and the cracks on the edge are create. Due to it the surface roughness is changed and start material defects [8]. So it is a very important to machined workpiece with same mechanical and structural properties in one time to save idle times.

\section{Analysis of the current problem}

For gears 18CrNiMo7-6 is used. Main problem during the machining is material plucking on the gear teeth during hobbing. This defects were monitored only during machining same type of the machined materials. For example when the main contractor made new batch of the casting. Second problem was when the plucking start create the cutting tool life is change too. These means that the operators must start to solve these problems and total machining time rapidly increase. These problems influence the future problems which is monitored after grinding, heat treatment etc., see Fig. 1.

a

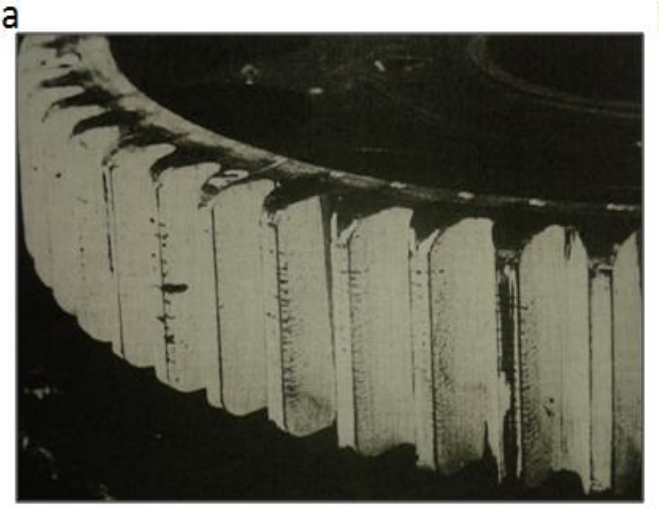

b

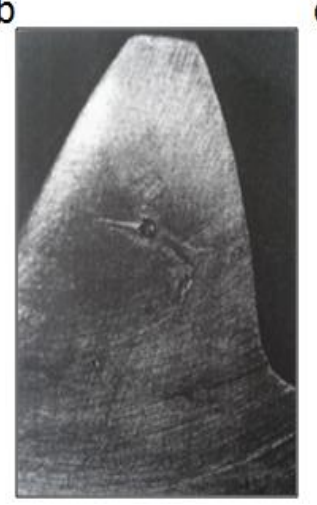

C

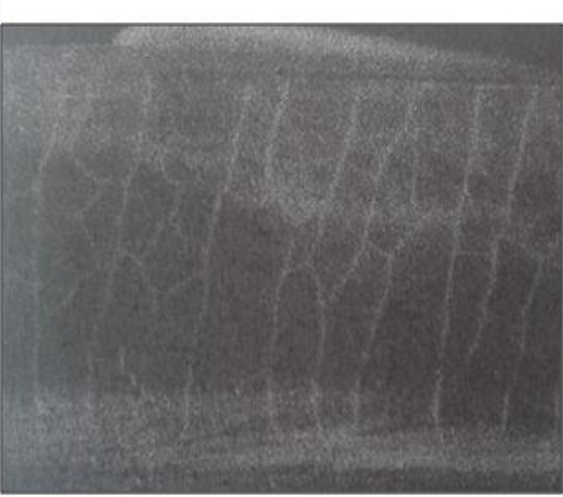

Fig. 1. (a) cracks after hardening; (b) fatigue cracks; (c) cracks after grinding. [1]

For tests the simplified variant of the experiment were used. From three different contractors the workpiece was used. Everybody have exactly describe request for the material properties and structure which was in accordance with the standard. For the machining standard monolith face mills from tool steel were used.

\subsection{Material analysis}

For the experiment three different materials were used from three different producers. At the beginning the main material properties were monitored.

\subsubsection{Hardness}

For the measuring of the hardness the Brinell test was used. Tab. 1 shows the average value from the test where a lot of measuring were made on one testing material in many places on surface and on the face. 


\begin{tabular}{llll}
\hline No. of the smithy & $\begin{array}{l}\text { Hardness HB } \\
\text { (workpiece 1) }\end{array}$ & $\begin{array}{l}\text { Hardness HB } \\
\text { (workpiece 2) }\end{array}$ & $\begin{array}{l}\text { Hardness HB } \\
\text { (workpiece 3) }\end{array}$ \\
\hline 1 & 242 & 248 & 255 \\
2 & 242 & 242 & 242 \\
3 & 167 & 160 & 171 \\
\hline
\end{tabular}

Table 1. Average hardness of the testing material

How the table shows, hardness of the material from smithy 1 and 2 is similar but material from smithy 3 has lower hardness about 30\% HB.

\subsubsection{Roughness}

\begin{tabular}{llll}
\hline No. of the smithy & $\begin{array}{l}\text { Roughness Ra }[\mu \mathrm{m}] \\
(\text { workpiece 1) }\end{array}$ & $\begin{array}{l}\text { Roughness Ra }[\mu \mathrm{m}] \\
(\text { workpiece 1) }\end{array}$ & $\begin{array}{l}\text { Roughness Ra }[\mu \mathrm{m}] \\
\text { (workpiece 1) }\end{array}$ \\
\hline 1 & 0,36 & 0,41 & 0,58 \\
2 & 0,6 & 0,36 & 0,32 \\
3 & 0,35 & 0,43 & 0,3 \\
\hline
\end{tabular}

Table 2. Average roughness after first hobbing on the tooth flank

For these test the same material from same meltage was used like testing material. Value from this measuring shows the same parameters with small differences. So from this test is not possible identify differences between the material properties.

\subsubsection{Microstructure and microhardness}

For this analysis the specimen from place of the edge and in the middle of the workpiece were used. How the Tab. 3 shows it is evident the differences between the materials structure and microhardness of the specimen.

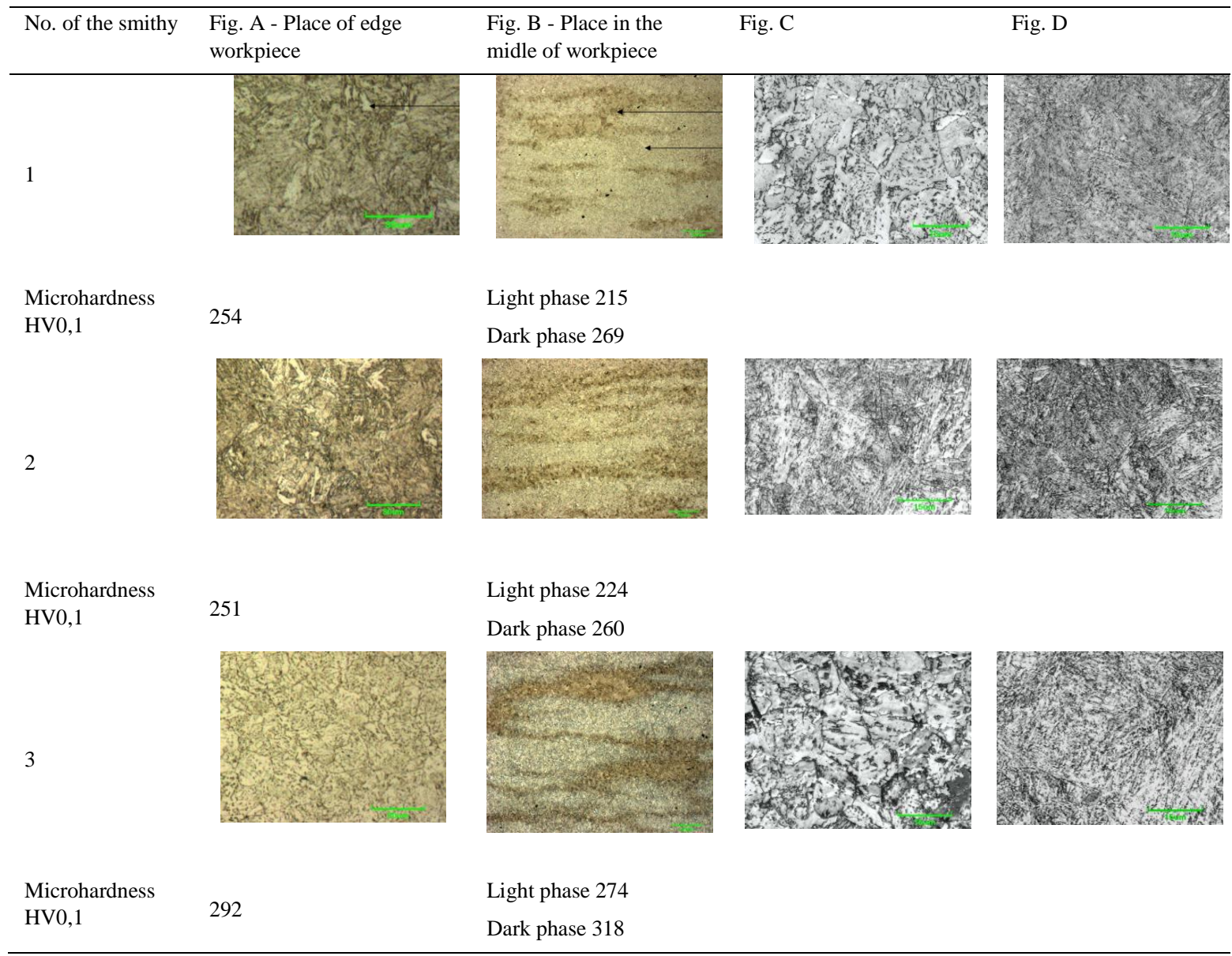

Table 3. Average roughness after first hobbing on the tooth flank 
The next is differences between the microstructure of the edge and in the middle of the workpiece. This problem is occurs in all samples. In area of the edge workpiece the structure is formed by ferritic matrix with cementite and ferrite grains rare (Table 3 - Fig. A), in samples from the middle area is evident banding structure (Table 3 - Fig. B). The detail analyses confirm different morphology of the cementite in light and dark places. In light area the cementite create course clusters which are excluded grain boundery and inside grain (Table 3 - Fig. C). In dark area the cementite is ruled like fine particles and homogeneously distributed within the grains.

\subsection{Machining process analysis}

During the machining cutting tool life and forces were monitored. Cutting conditions were close to the real conditions and the final set up shows Tab. 4.

\begin{tabular}{ll}
\hline Parameter & Value \\
\hline Cutting speed $[\mathrm{m} / \mathrm{min}]$ & 55 \\
Feed per teeth $[\mathrm{mm}]$ & 0,08 \\
Axial depth of cut $[\mathrm{mm}]$ & 15 \\
Radial depth of cut $[\mathrm{mm}]$ & 0,8 \\
Cutting environment & oil \\
\hline
\end{tabular}

Table 4. Cutting conditions

\subsubsection{Cutting Tool Wear}

The maximum tool wear was setup $\mathrm{WBB}=150 \mu \mathrm{m}$. But after the first test this parameters was changed because when value of the tool wear was along 100 -120 $\mu \mathrm{m}$ the temperature in cut rapidly increase. It causes machined surface heat influence which causes in other cut the cutting edge or cutting tool or machined surface damage. On the base of this fact the tool wear was compared in the same time and it was evaluated the influence of the workpiece on the tool wear in one time.

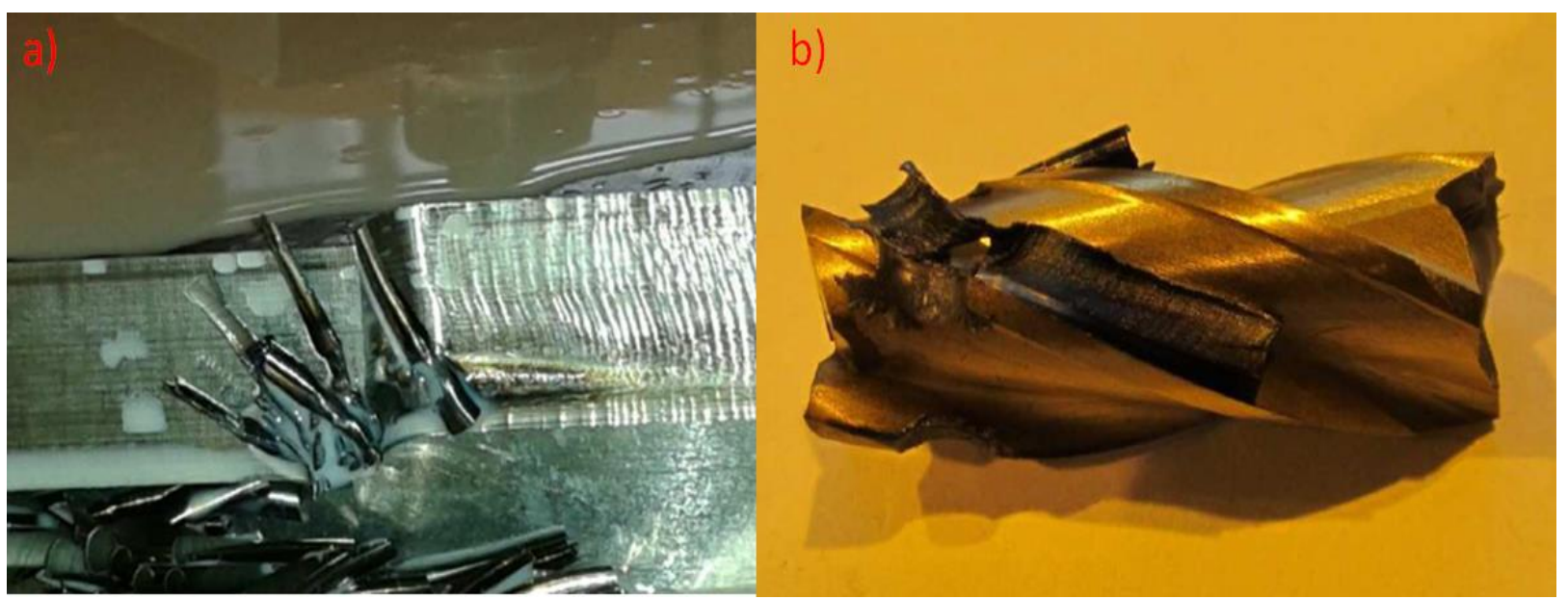

Fig. 2. (a) Damage of the machined surface; (b) Damaged cutting tool

The graph shows the maximum tool wear has cutting tool when machined material from the smithy 3 . This result is consistent with theory because the structure microhardness of this material is the hardest. The next the chip color and shape were monitored. The colour is different too between the tasted material and the results correspond with the workpiece microhardness and hardness too. 
Tool wear in time $4 \mathrm{~min}$

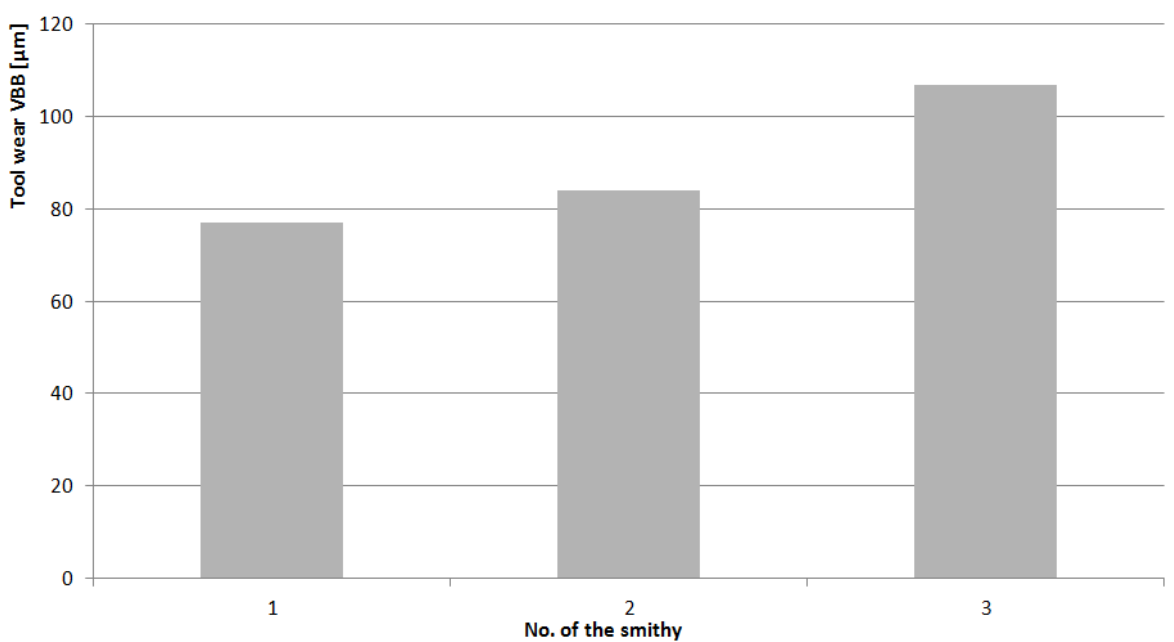

Fig. 3. Value of the cutting tool wear in time $4 \mathrm{~min}$

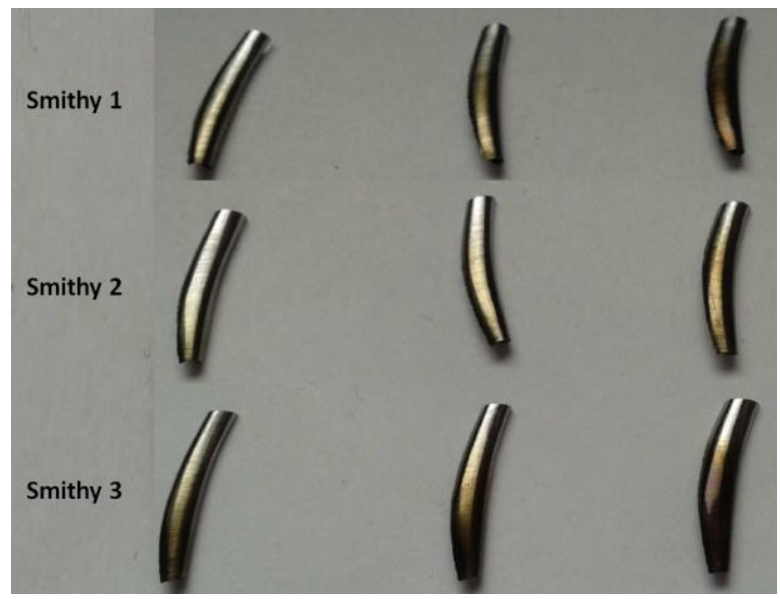

Fig. 4. Different color of the chip (On the left - new cutting tool, on the right - cutting tool with tool wear at the end of the test)

\subsubsection{Cutting force}

For the measuring the dynamometer Kistler Type 9225A was used and the force in the axial direction X, Y, Z were evaluated. The biggest one force was in axis X - FX which is compared in the graph for the testing material.

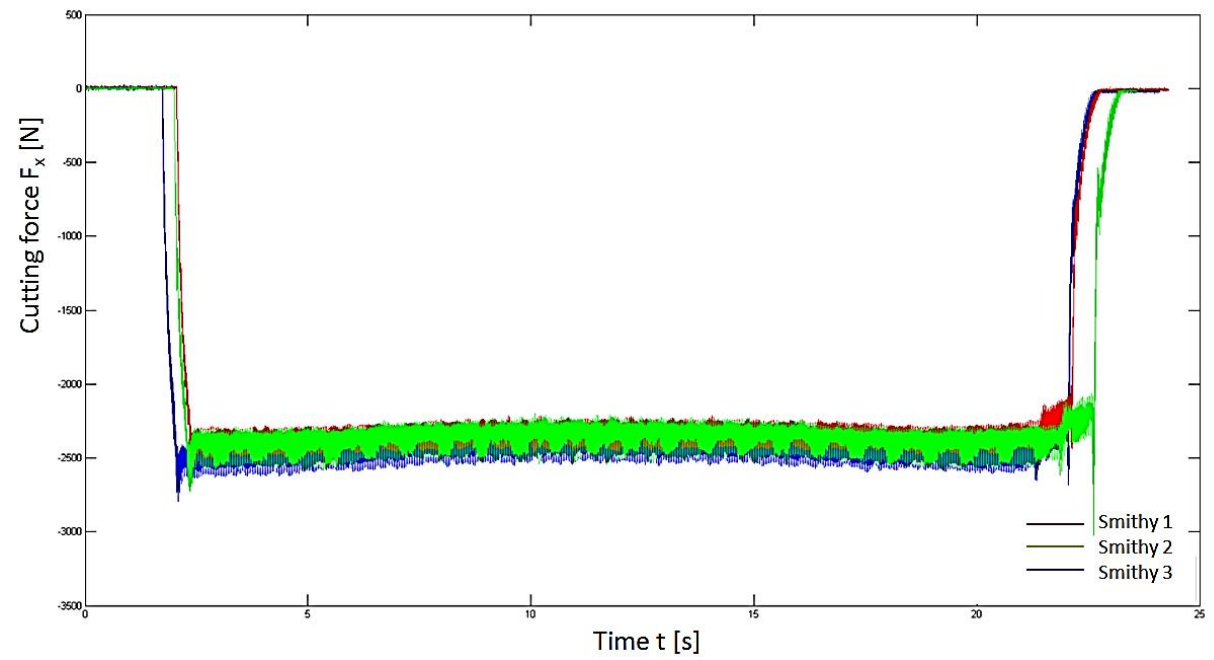

Fig. 5. Value and curve of the cutting force Fx. 
Value of the cutting force are close similar however the biggest value have cutting tool which machined workpiece from smithy 3. Probably it is causes by the same reasons like before.

\section{Conclusion}

At the beginning in the real process of the machining gear wheels were monitored problem of the quality machined surface and cutting tool life. On the base of it were prepare this experiment which solved if the material producers (smithy) could influence these problematic parameters which influence the company productivity. The results shows that yes and very important. However it is strange that all of the smithy received same request on parameters of the material properties which were defined by the chemical composition, mechanical properties and heat treatment. When we will study all of these process little close these results shows that the main problem is in final material structure. It was found that the micro structure is different at the edge of the workpiece and in the middle and in different places are different composition of the material structure with different properties. This causes the changes during machining and it influence the future problems on the teeth after the machining and during real process of the gear life. At this time the winner smithy have precisely instructions about the material structure and they must abide the heat and forging processes. It causes that the machining process is reliable, the lost machining time is remove and the company safe money and increase productivity.

\section{Acknowledgements}

The present contribution has been prepared under project LO1502 'Development of the Regional Technological Institute " under the auspices of the National Sustainability Programme I of the Ministry of Education of the Czech Republic aimed to support research, experimental development and innovation.

\section{References}

[1] Younes Ramdane, Hamzaoui Nacer, Ouelaa Nouredine, Djebala Abderrazek, Perceptual study of the evolution of gear defects, Applied Acoustics 99 (2015) 60-67.

[2] Rozmarina Dubovska, Jozef Majerik, The Research Analysis of Surface Finish and Wear on the Special Tribological Device, Procedia Engineering 100 ( 2015 ) 730-736.

[3] Adis J. Muminovic, Isad Saric, Nedzad Repcic, Numerical Analysis of Stress Concentration Factors, Procedia Engineering 100 ( 2015 ) 707-713.

[4] Rozmarina Dubovska, Jaroslav Jambor, Jozef Majerik, Qualitative Aspects of Machined Surfaces of High Strength Steels, Procedia Engineering 69 ( 2014 ) 646 - 654.

[5] Libor Beránek, Kamil Kolař́ík, Surface integrity analysis of duplex steel by design of experiment approach, Procedia Engineering 69 ( 2014 ) $630-637$.

[6] Jana Moravčíková, Cutting Material Influence on the Quality of the Machined Surface, Procedia Engineering 100 ( 2015 ) $328-333$.

[7] Marco Sortinoa, Sandro Belfio, Giovanni Totis, Elso Kuljanic, Giovanni Fadelli, Innovative Tool Coatings for Increasing Tool Life in Milling

Nickel-Coated Nickel-Silver Alloy, Procedia Engineering 100 ( 2015 ) 946 - 952.

[8] Tomáš Vopát, Jozef Peterka, Vladimír Šimna, Marcel Kuruc, The Influence of Different Types of Copy Milling on the Surface Roughness and Tool Life of End Mills, Procedia Engineering 100 ( 2015 ) 868 - 876 